DOI: $10.33764 / 2687-041 X-2021-1-45-49$

\title{
ПРИМЕНЕНИЕ ПРОГРАММНОГО ОБЕСПЕЧЕНИЯ NЕТСАD ПРИ ГЕОДЕЗИЧЕСКОМ СОПРОВОЖДЕНИИ ОТКРЫТОГО МЕСТОРОЖДЕНИЯ БУРОГО УГЛЯ
}

\author{
Данияр Кулатаевич Амерханов \\ Сибирский государственный университет геосистем и технологий, 630108, Россия, г. Новоси- \\ бирск, ул. Плахотного, 10, обучающийся, тел. (778)431-00-05, e-mail:daniyar.amerkhanov@gmail.ru
}

\section{Елена Геннадвевна Гиенко}

Сибирский государственный университет геосистем и технологий, 630108, Россия, г. Новосибирск, ул. Плахотного, 10, кандидат технических наук, доцент кафедры космической и физической геодезии, тел. (383)361-01-59, e-mail:elenagienko@yandex.ru

Рассмотрены функциональные возможности программного обеспечения Netcad, в частности, применение одного из модулей для решения инженерно-технических задач по геодезическому сопровождению открытого месторождения бурого угля.

Ключевые слова: программное обеспечение Netcad, открытое месторождение, геологическое строение, 3D-моделирование, геодезическое обеспечение

\section{APKLIKATION OF NETCAD SOFTWARE FOR GEODETIC SUPPORT OF OPEN BROWN COAL DEPOZIT}

\section{Daniyar K. Amerkhanov}

Siberian State University of Geosystems and Technologies, 10, Plakhotnogo St., Novosibirsk, 630108, Russia, Student, phone: (778)431-00-05, e-mail: daniyar.amerkhanov@gmail.ru

\section{Elena G. Gienko}

Siberian State University of Geosystems and Technologies, 10, Plakhotnogo St., Novosibirsk, 630108, Russia, Ph. D., Associate Professor, Department of Space and Physical Geodesy, phone: (383)361-01-59, e-mail: elenagienko@yandex.ru

The functionality of the Netcad software is considered, in particular, the use of one of the modules for solving engineering and technical problems on geodetic support of an open brown coal deposit.

Keywords: Netcad, field, wells, application, geological structure, modeling

\section{Введение}

Netcad - это программа общего назначения для САПР (автоматизированного проектирования) и ГИС (географических информационных систем). Это многофункциональная, проверенная и единственная Турецкая национальная программа САПР и ГИС по международным стандартам. Ha Netcad разработано около 30 базовых приложений [8]. 
По состоянию на 2007 год насчитывалось около 5000 пользователей и 15000 действующих пользовательских лицензий Netcad. На данный момент насчитывает более 125 сотрудников и имеет офисы в Анкаре и Стамбуле. Netcad является универсальной программой, благодаря многочисленным модулям позволяет решать практически любые задачи в сфере геодезии и землеустройства [8].

Наиболее востребованными модулями являются:

- netsurf - набор классов программного обеспечения и пользовательских интерфейсов, разработанных для создания цифровой модели местности и отрисовки рельефа;

- netmap -для зонирования и подготовки кадастрового проекта, включая координатные расчеты. Имеет стандартную структуру благодаря использованию файлов шаблонов при создании проекта;

- netpro -для проектирования и расчета объема выполненных работ, таких объектов, как автомобильные дороги, железные дороги, аэропорты, гавани, плотины, планирование жилых районов и археологические работы;

- Netpro/Mine - позволяет отслеживать все этапы добычи начиная от геологоразведки и заканчивая рекультивацией в открытых месторожденияx[8].

Широкое внедрение и использование средств вычислительной техники во всех отраслях науки и производства приводит к качественному изменению многих технологий и появлению новых программных обеспечении. Одним из таких направлений в топографо-геодезическом производстве стало создание и усовершенствование программных обеспечений [2].

Актуальность данной темы заключается в необходимости ускорения геодезических расчетов с помощью новых программ. Netcad позволяет быстро и качественно проектировать и производить вычисления объемов работ всех типов линейных сооружений. Внедрение и использование данной программы способствует эффективности производства многих видов геодезических работ и технических работ [1].

В данной публикации использованы материалы из личного опыта работы на карьере в Турецкой Республике. С помощью одного из модулей программного обеспечения Netcad была создана трехмерная модель каждой скважины, что в дальнейшем позволило произвести расчеты и узнать объем добываемого ископаемого материала для каждого пласта [5].

\section{Методы и материалы}

Территорией для исследования является месторождение бурого угля между городами Афшин и Эльбистан. В качестве геодезической основы будут использованы результаты ранее выполненных инженерно-геодезических и геологических работ, где были сделаны 280 скважин, у которых определены координаты и высоты. Схема расположения скважин приведена на рис. 1. 
Для выполнения исследования будет использовано приложение Netpro/Mine, это приложение является одним из модулей программного обеспечения Netcad.

Разработчики Netcad, Университет горного машиностроения города Газтепе и Технический университет Стамбула, совместно разработали данное приложение для решения геодезических и геологических задач на открытых месторождениях полезных ископаемых. Приложение позволяет отслеживать все этапы добычи, начиная от геологоразведки и заканчивая рекультивацией месторождения.

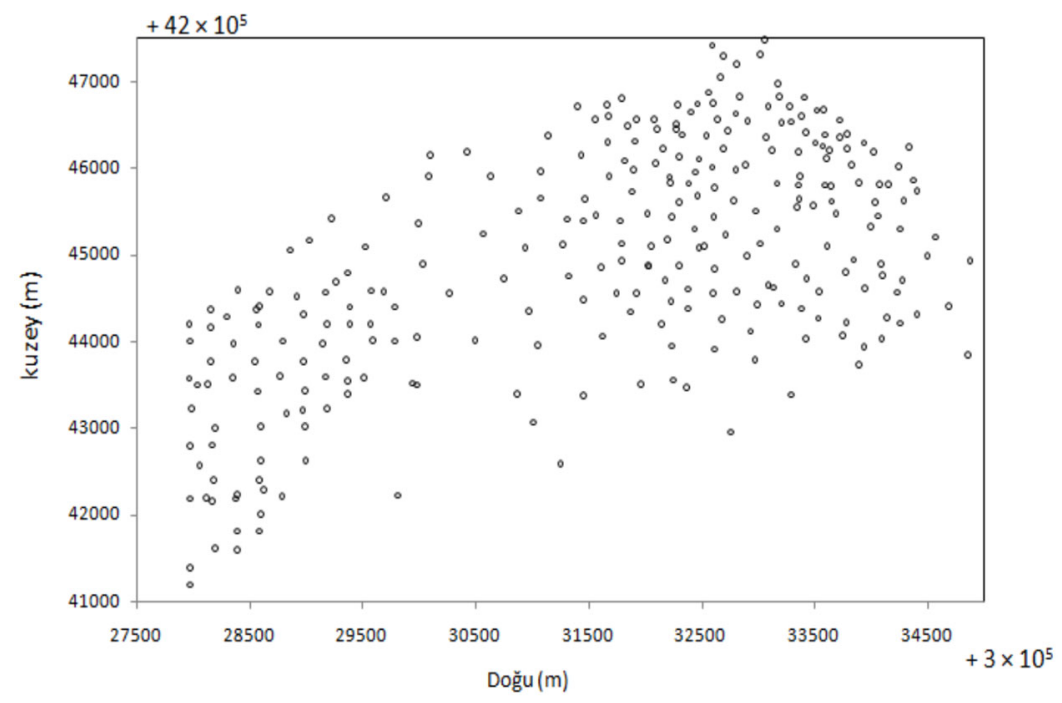

Рис. 1. Схема скважин

Netpro / Mine запустила свое инженерное приложение в декабре 2010 года, которое ежегодно обновляется и усовершенствуется.

B Netpro / Mine выполняется ввод данных, где должны быть указаны следующие данные: Номер скважины, глубина, X, Y, Z, геологическое строение. Также можно выполнить импорт с формата *csv. Пример указан на рис. 2.

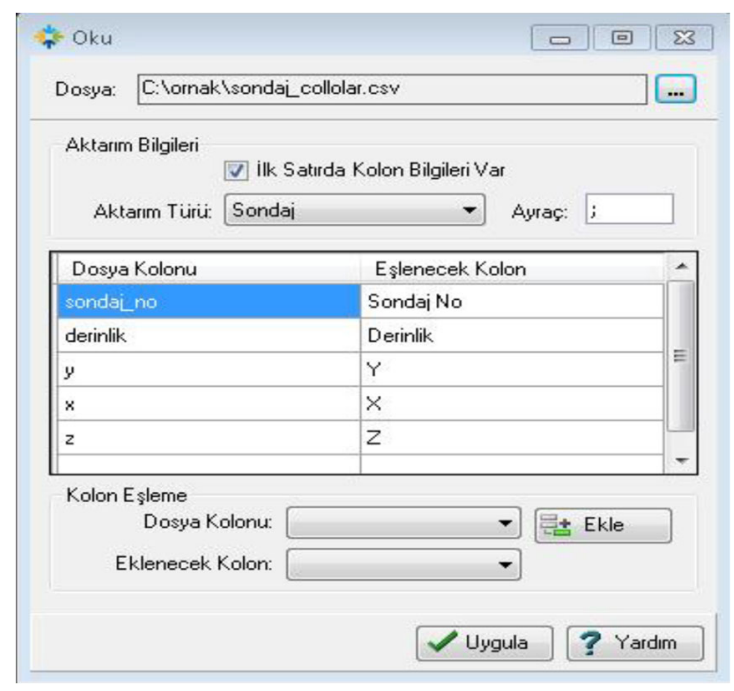

Рис.2. Фрагмент окна импорта данных 
Так как глубина заложения скважин разная, с помощью специального меню их можно привести в один условный горизонт. Для наглядности можно осмотреть скважины в 3D формате, как показано на рис. 3.

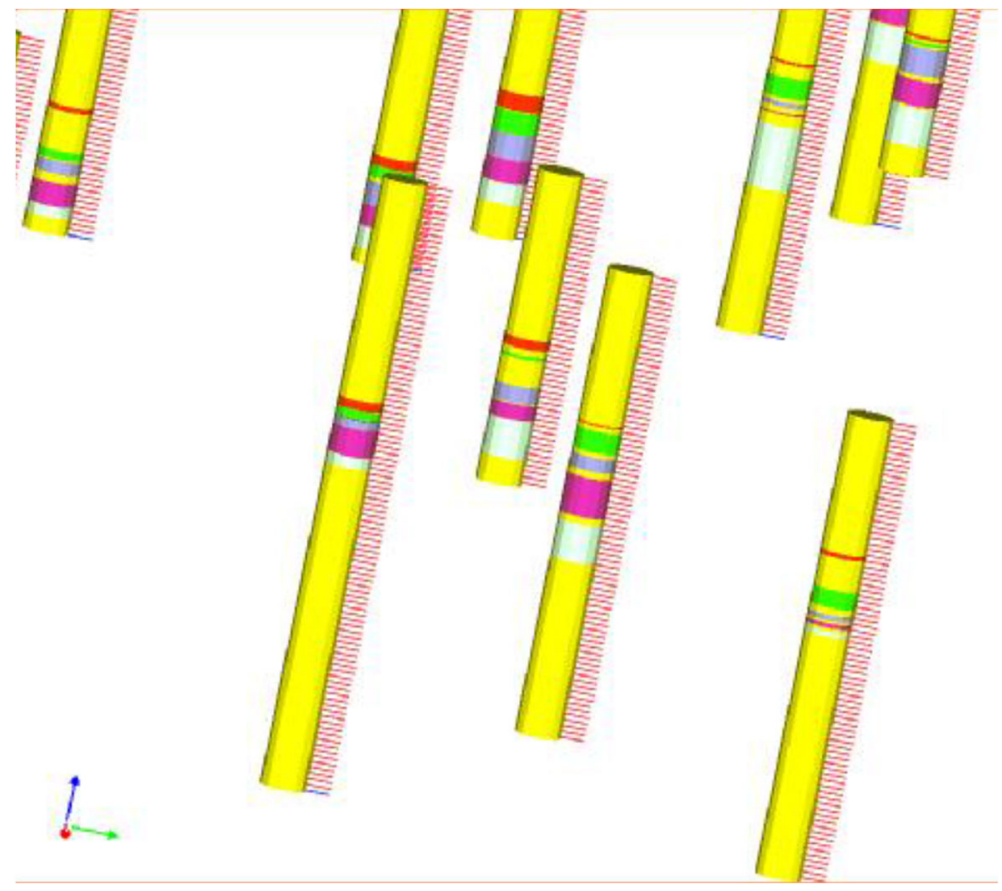

Рис.3. Изображение скважин в 3Dформате

После можно произвести отбор скважин схожих по геологическому строению. Приложение автоматически сгенерирует триангуляцию и определит объем ископаемых для каждого литологического слоя, [3]. Для каждого слоя выполняется моделирование, и для наглядности можно увидеть разрез литологического слоя, как показано на рис. 4.

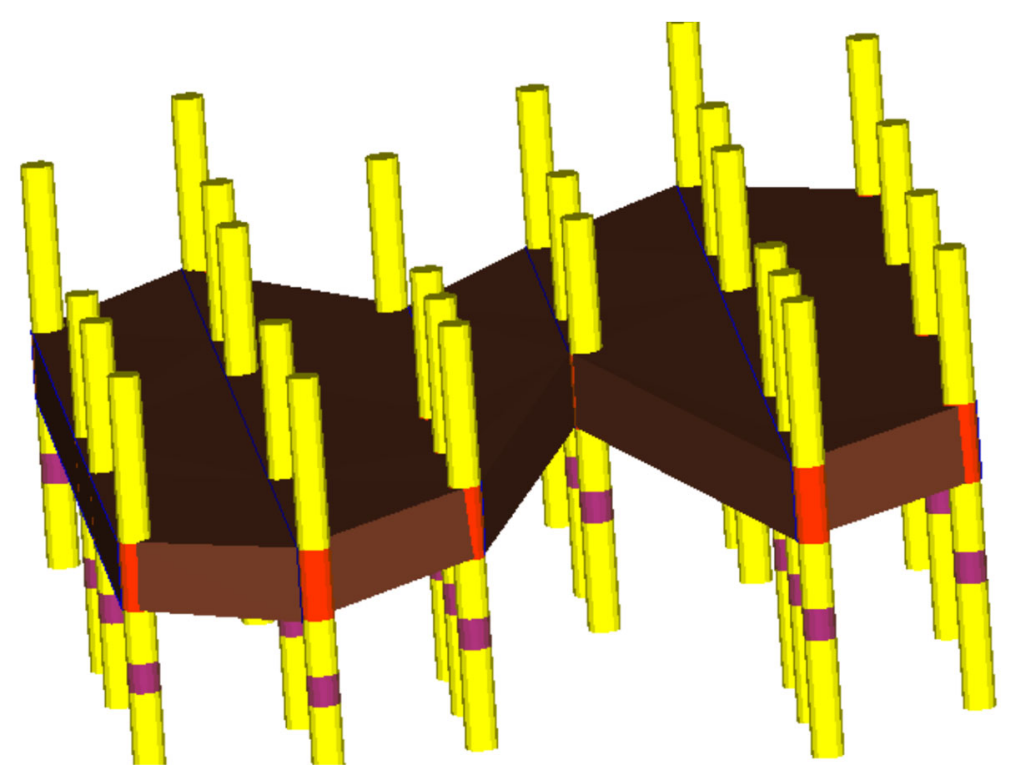

Рис. 4. Разрез литологического слоя 
Структура распределения слоев определяется путем анализа сводной статистики и гистограмм [4].

C помощью модуля Netpro/Mineможно получить следующие данные:

- оценка данных бурения;

- параметры оптимального горизонта;

- послойное моделирование;

- блочное моделирование;

- отчет по качеству бурения скважин;

- тематическая схема скважин.

C помощью данной программы также можно определить количество полезных ископаемых, в данном случае бурого угля, и определить объем сопутствующих пород [7]. Согласно разработанному учебному пособию Порцевского А.К. [6] есть возможность классифицировать полезные ископаемые по качеству и типу.

\section{Результаты}

Работа с Netpro/Mine позволило в нашем случае сделать следующие выводы:

- модуль Netpro / Mine имеет достаточно простой интерфейс с широкими возможностями, позволяющие выполнять 2D и 3D операции в проектировании (CAD) и в географических информационных системах (GIS);

- с помощью сводной статистики возможно непосредственно вычислить вырабатываемую мощность каждого участка;

- возможно выполнять моделирование каждого слоя месторождения;

- с помощью схемы моделирования удобно определять объем каждого слоя полезных ископаемых;

- имеется возможность полного прогнозирования добычи на месторождении.

\section{БИБЛИОГРАФИЧЕСКИЙ СПИСОК}

1. Васильев П.В. Гурьянова И.В., Компьютерная графика:учеб.пособие. - Белгород : Изд-во БелГУ, 2007. - 168c.

2. Васильев П.В. Прогнозирование раскрытия минералов при добыче ирудоподготовке по данным автоматического анализа изображений структур и текстурруд // Маркшейдерия и недропользование. - 2008 г. - №3. - С. 50-53.

3. Геоинформатика в рациональном недропользовании: Монография/ Издательскополиграфический комплекс НИУ БелГУ. - Белгород, 2011г. - С. 26-32, 80.

4. Гудков В.М. Васильев А.А., Николаев К.П., Прогноз и планирование качества полезного ископаемого. - М. : Недра, 1976. - 191 с.

5. Михелев Ю.Д., Лобанов А.А.Анализ возможностей программного обеспечения для работы с графическими данными//Геопрофи. - №4. - 2003 г. - С. 34-36.

6. Порцевский А.К. Управление качеством рудной массы на открытых горных работах: учебное пособие. - М. : МГОУ, 1998. - 44 с.

7. Соболева Е.Л., Архипова О.Б. Исследование возможностей геоинженерных САПР//ИнтерЭкспо Гео-Сибирь. - Т.1. - № 2, 2010 г. - С.42 - 45.

8. Руководство по эксплуатации NETCADNetpro/Mine [Электронный ресурс]. - Режим доступа: https://wiki.netcad.com.tr/pages/viewpage.action?pageId=216255127. 